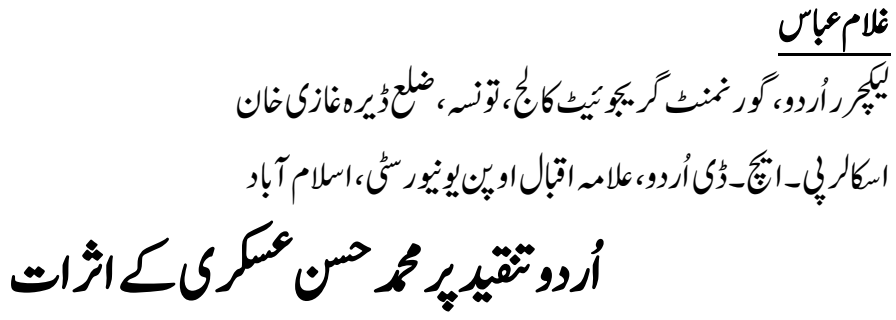

Ghulam Abbas

Lecturer Urdu, Govt Graduate College, Taunsa, Distt: Dera Ghazi Khan/ Ph.D research scholar Department of Urdu AIOU Islamabad.

\title{
Impacts of Hassan Askari on Urdu Criticism
}

Muhammad Hassan Askri is one of the key figures in Urdu literature. He cannot be ignored even in Urdu criticism. His criticism is a noble example of unusual critical insights and profound literary taste of twentyth century. His sphere of critical insights is noteworthy. He always opens new ways of discussion in the issues whether cultural or mystic, poetry or philosophy, art or literature and even in music. In this way, he has provided new information to new generation. His criticism influences the readers to the depth. His perceptions kept on changing and this has been considered as positive and accepted. So we can find the reaction of thoughts in his criticism. It is also true that the works against or in favour of his work is more than his original work. In this article views of a few leading and influential critics who subjected his scope of ideas, have been discussed.

Key Words: Urdu Literature, Criticism, Insights, Literary, Discussion, Cultural, Mystic, Philosophy.

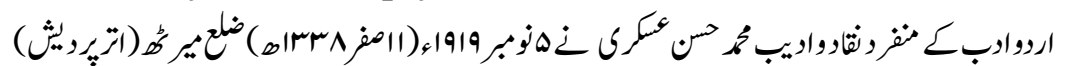

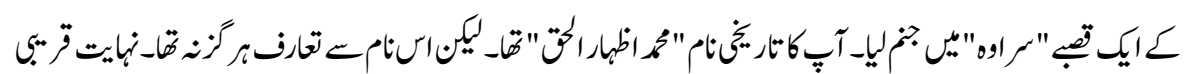

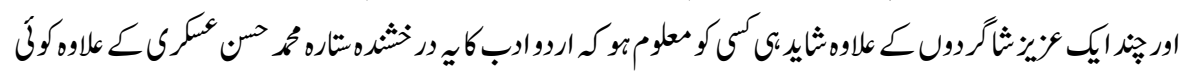

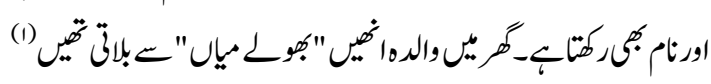

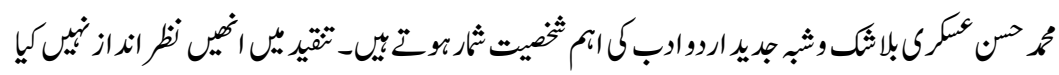

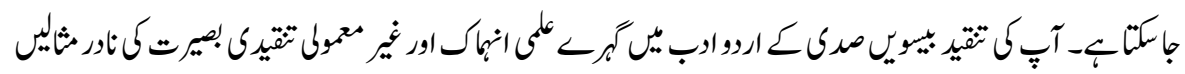




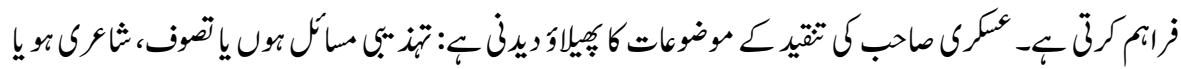

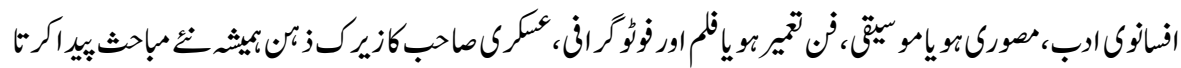

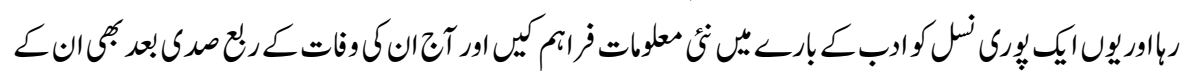

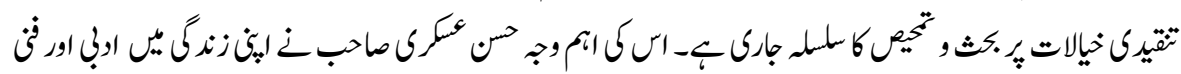

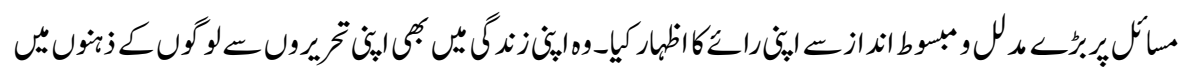

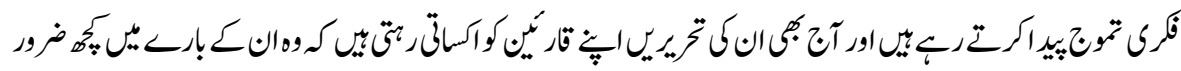

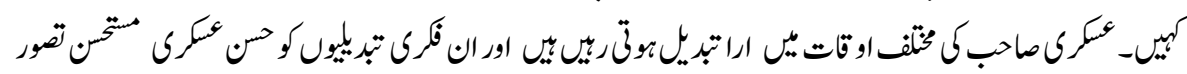

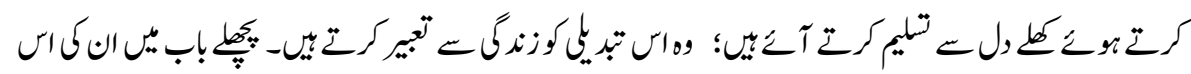

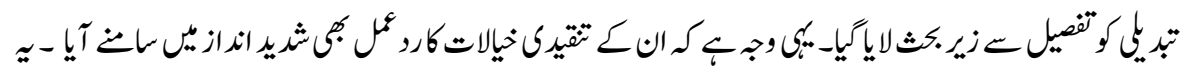

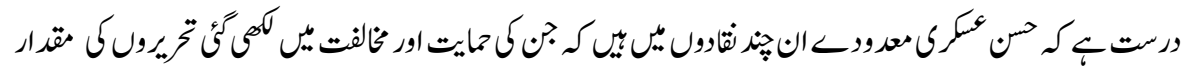

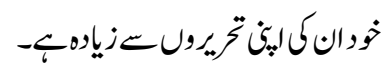

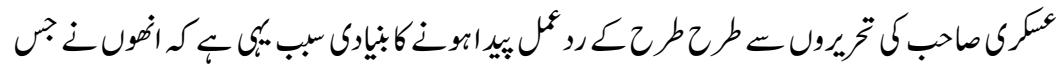

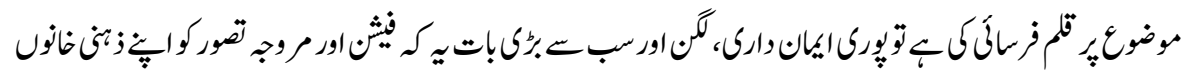

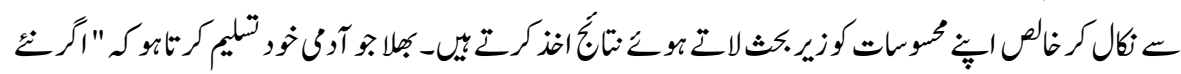

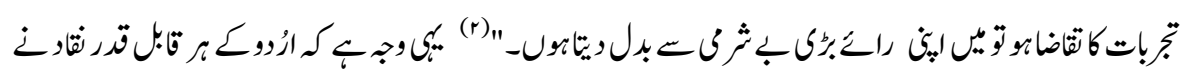

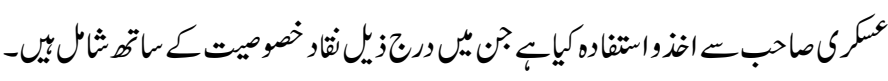

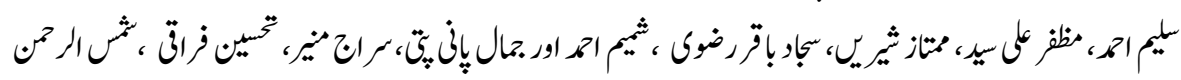

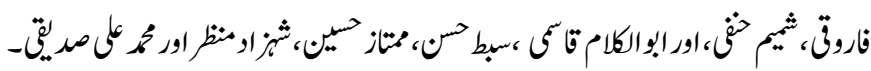

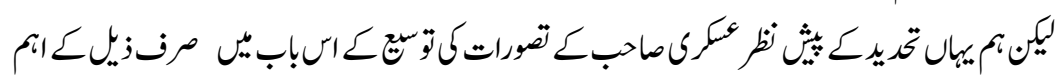

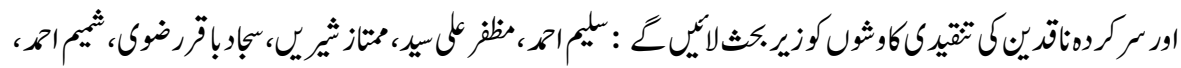

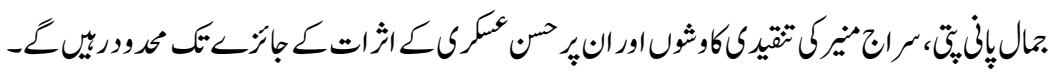

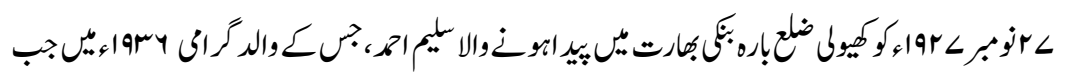

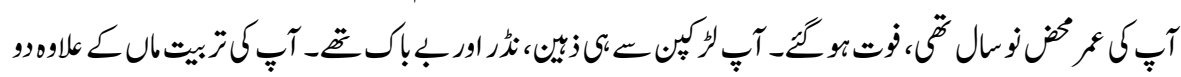

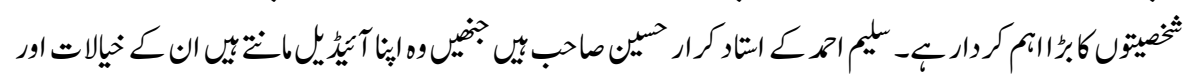




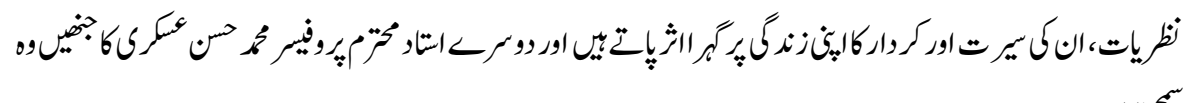

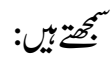

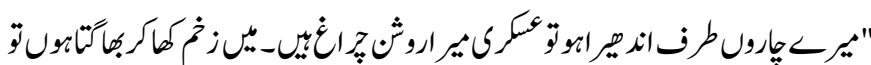

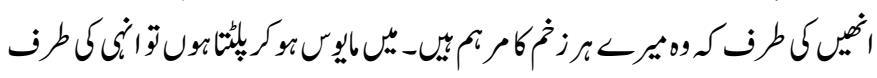

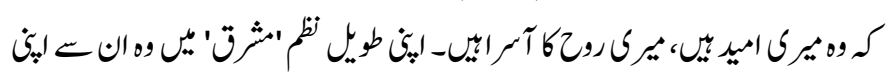

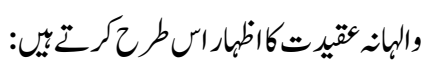

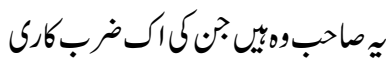

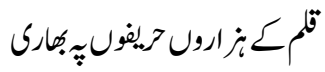

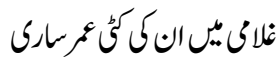

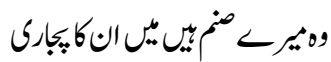

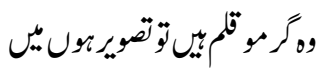

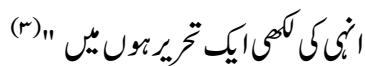

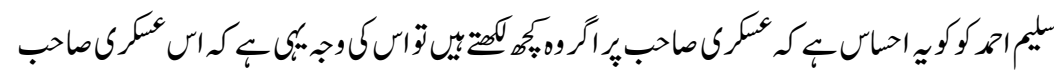

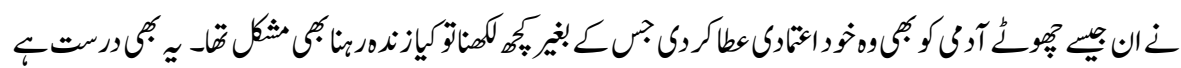

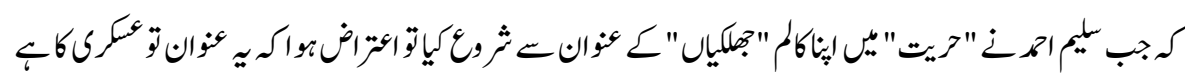

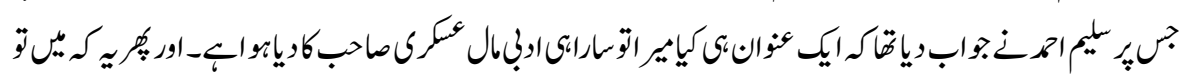

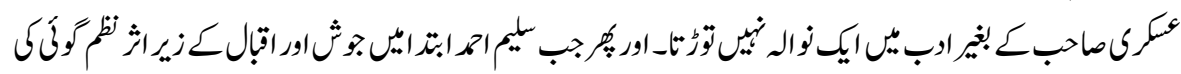

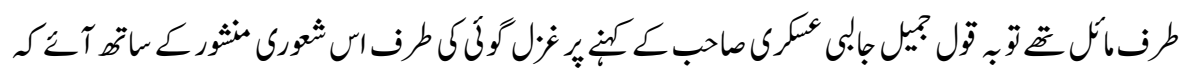

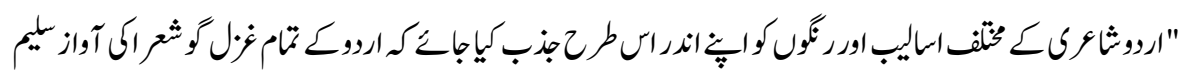

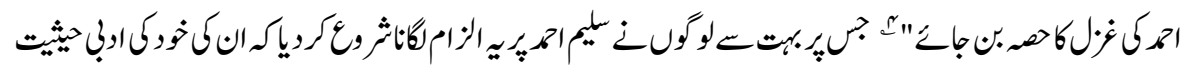

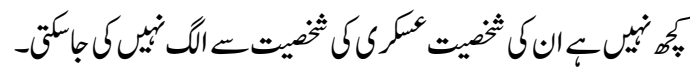

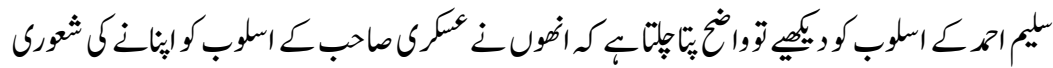

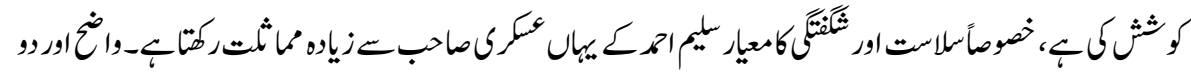

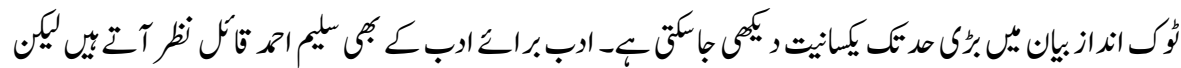

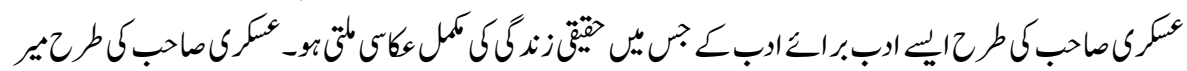




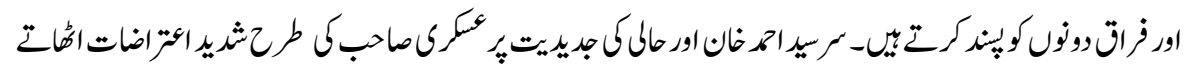

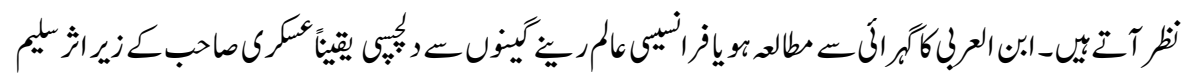

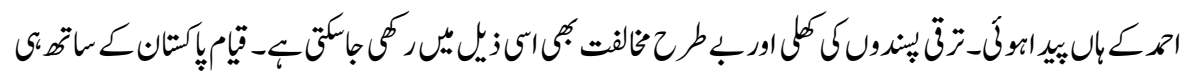

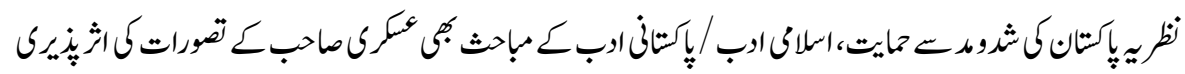

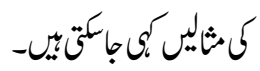

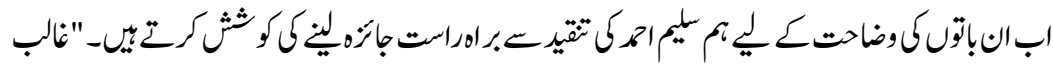

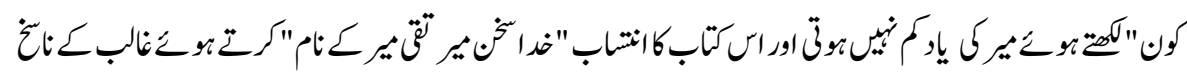

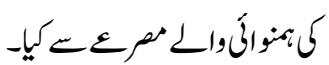

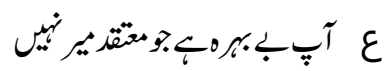

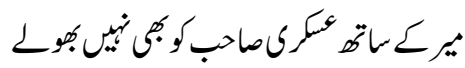

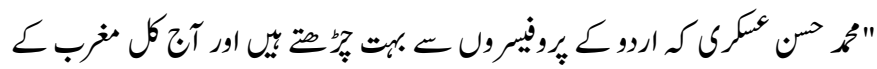

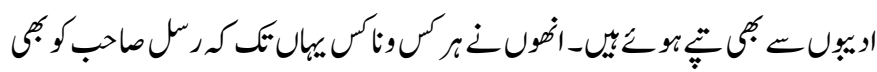

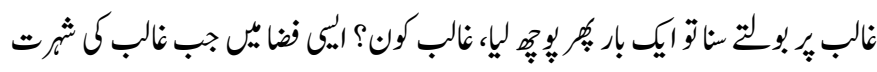

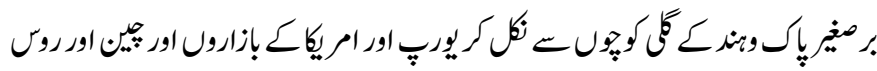

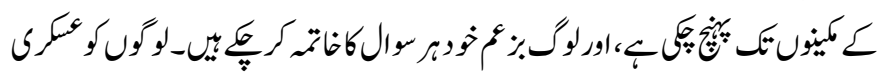

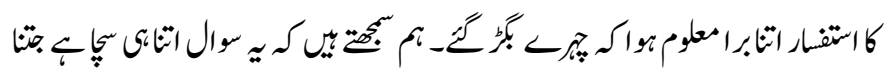

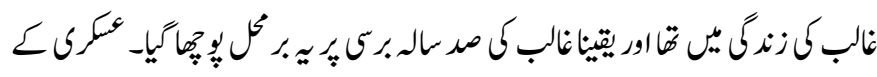

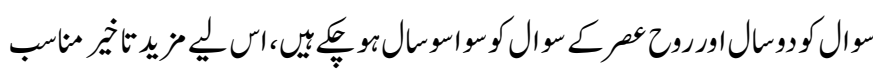

$$
\text { (ه)" }
$$

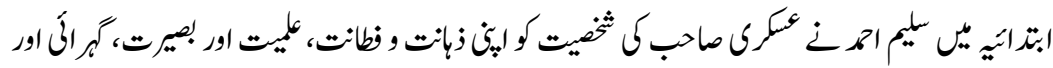

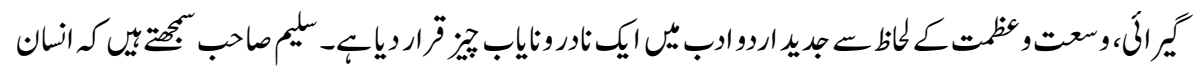

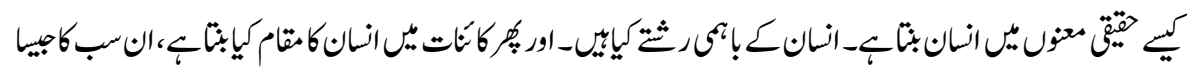

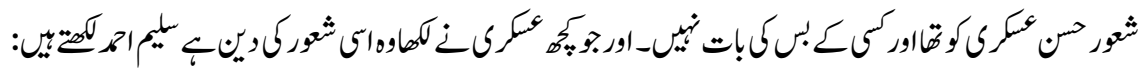

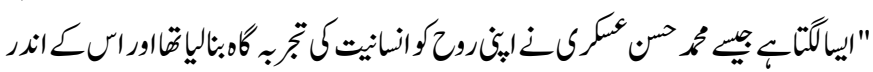

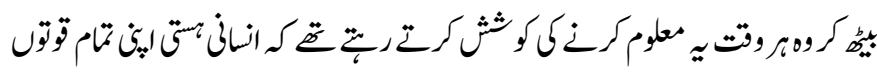




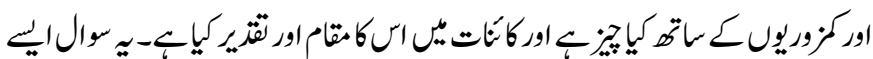

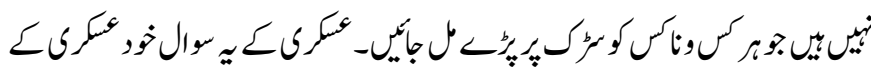

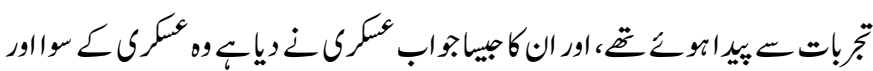

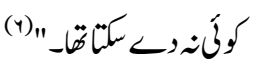

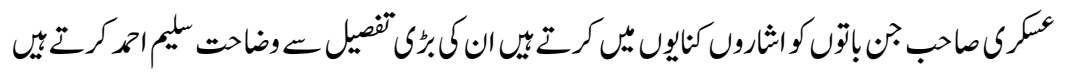

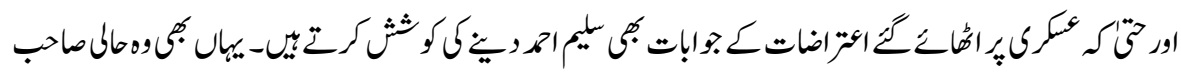

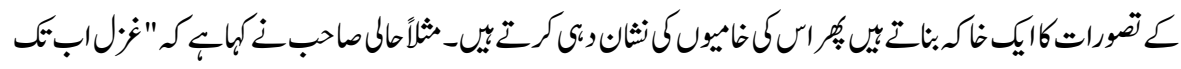

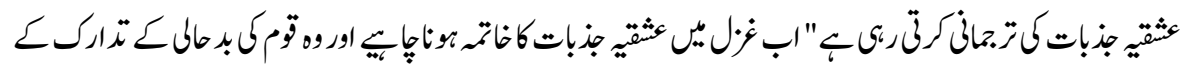

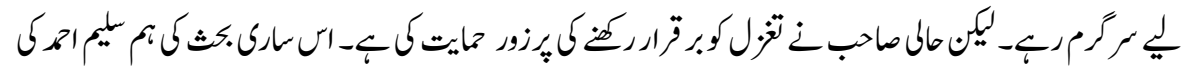

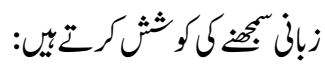

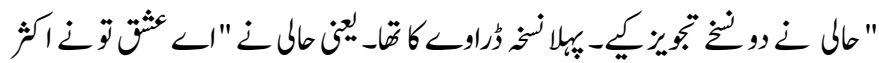

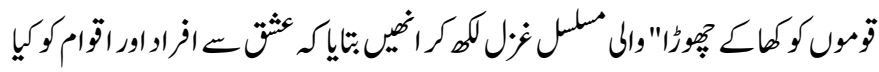

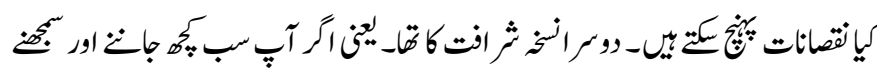

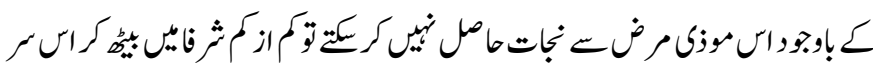

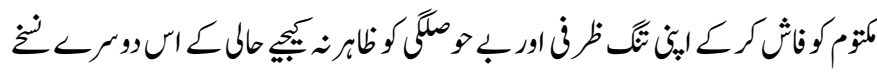

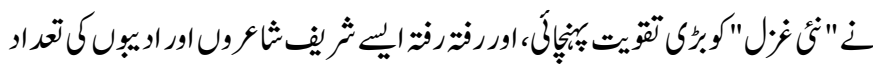

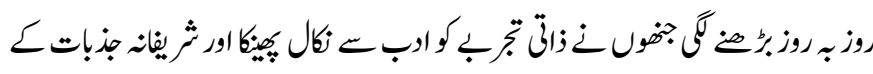

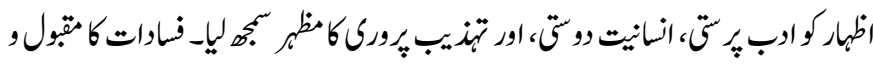

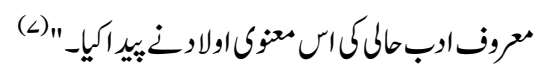

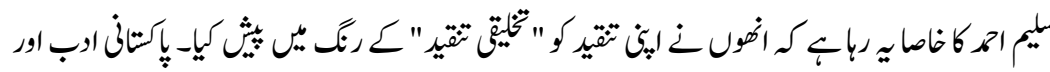

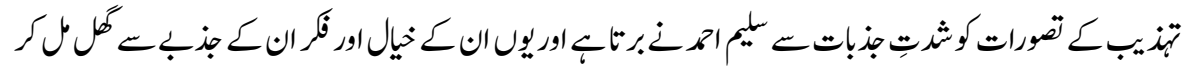

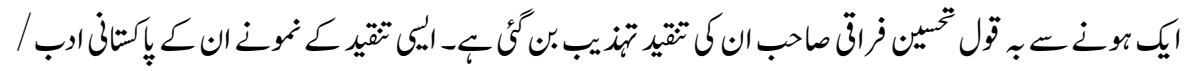

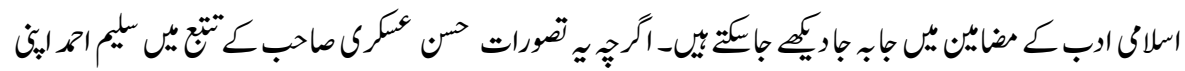

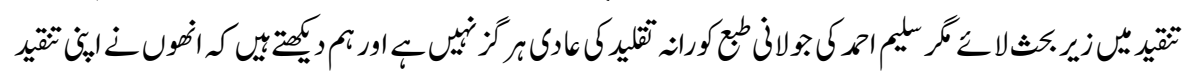

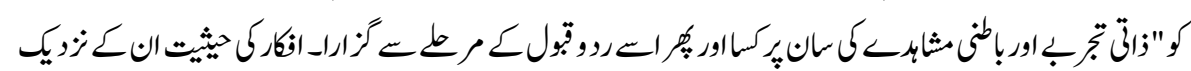




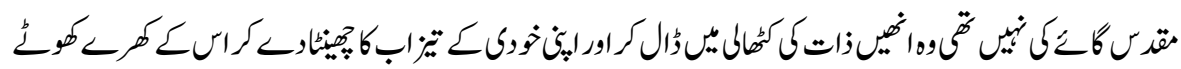

(1)"

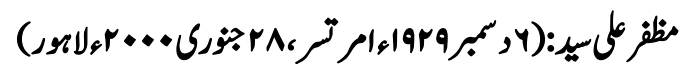

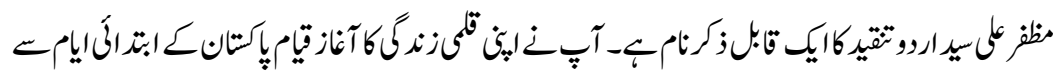

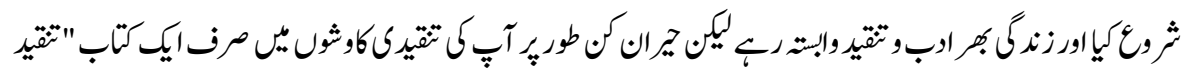

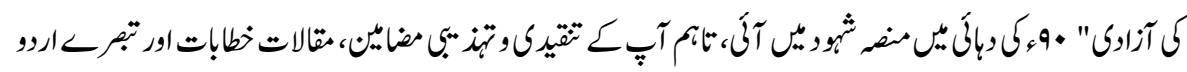

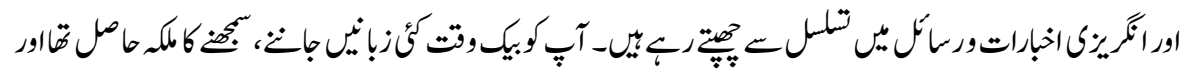

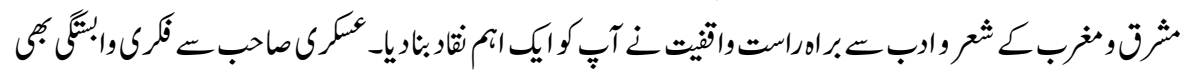

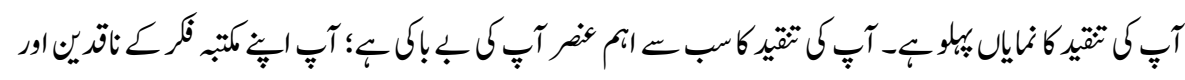

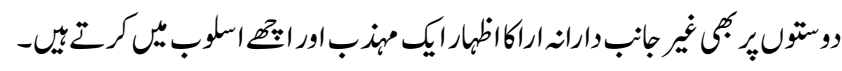

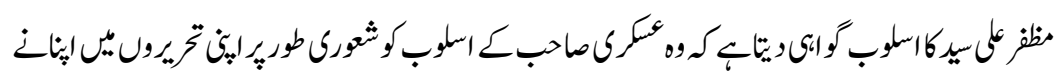

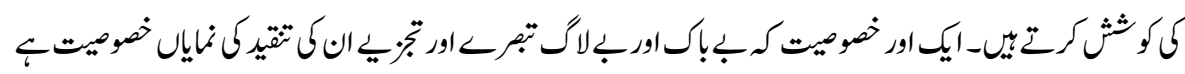

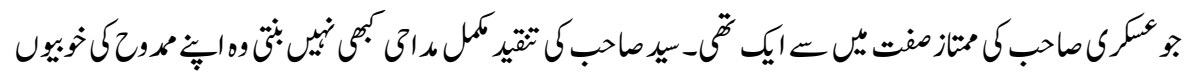

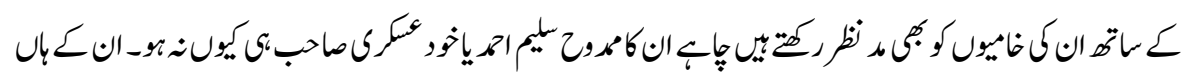

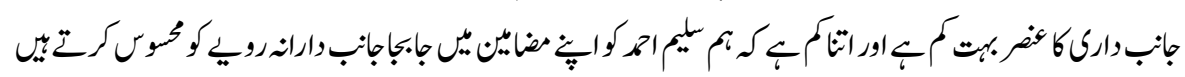

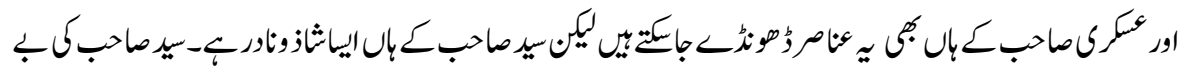

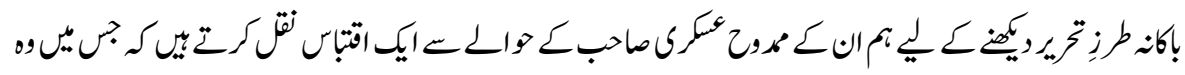

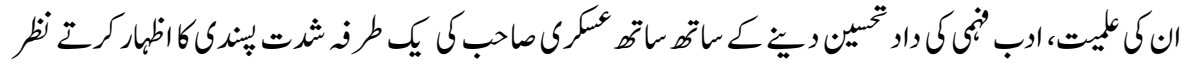

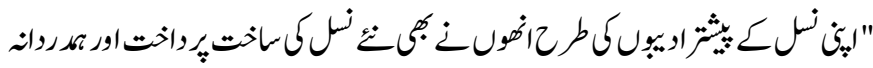

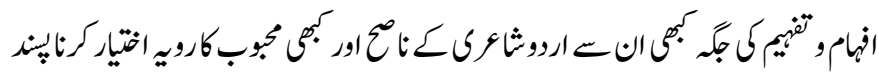

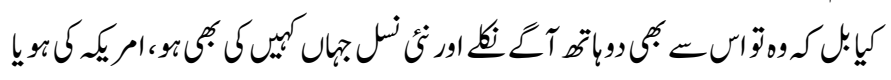

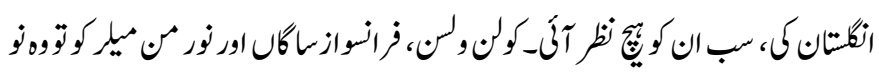

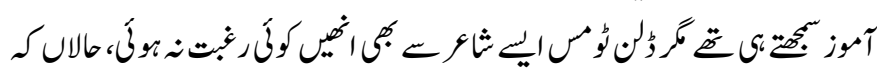

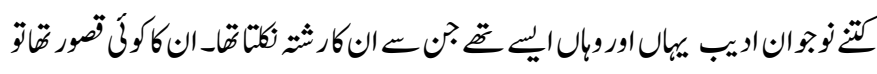




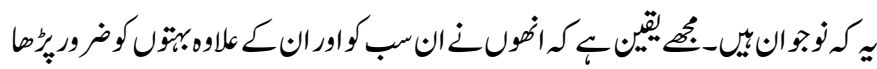

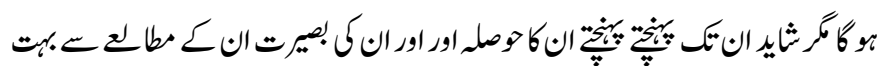
-

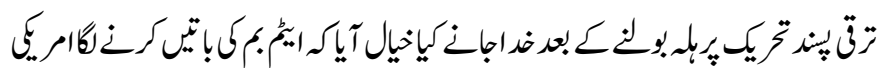

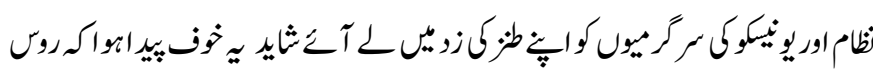

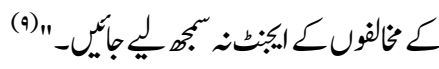

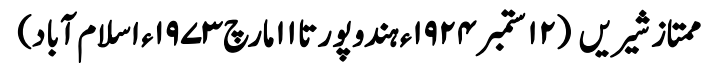

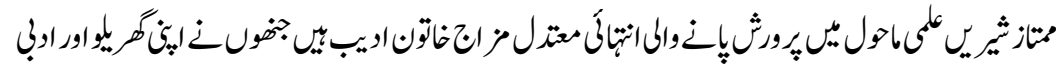

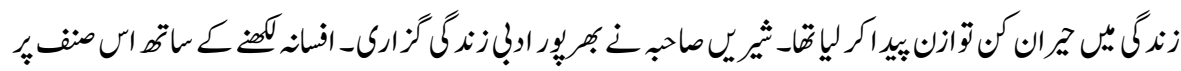

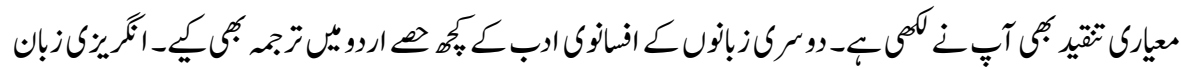

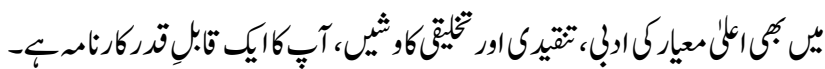

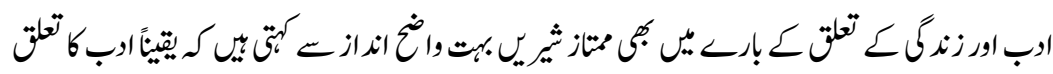

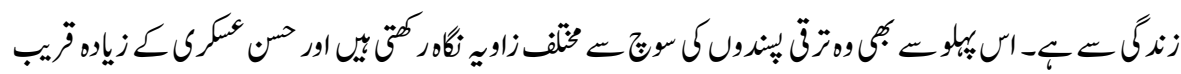

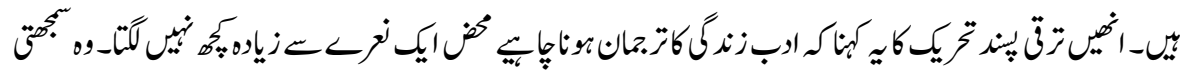

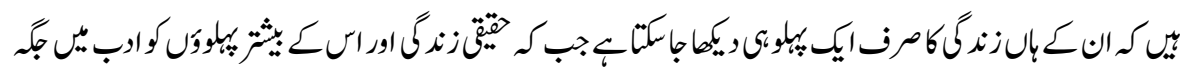

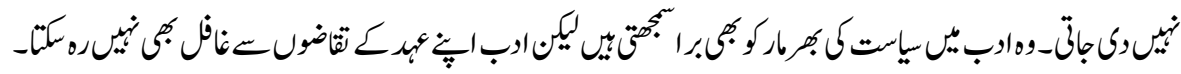

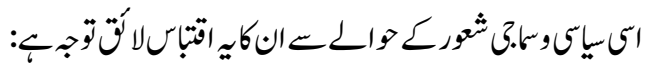

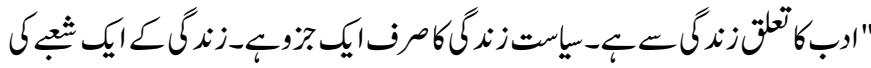

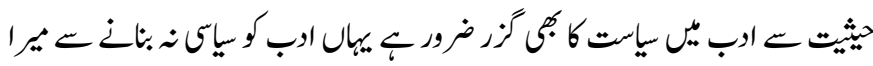

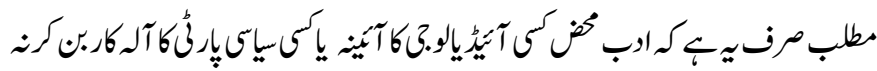

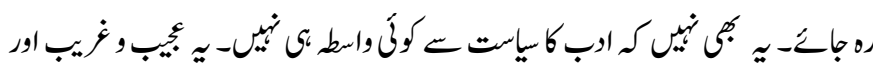

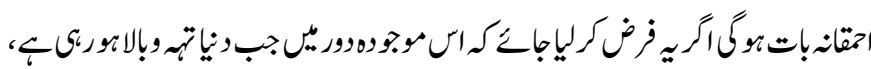

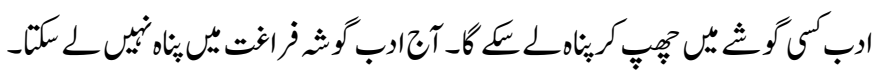

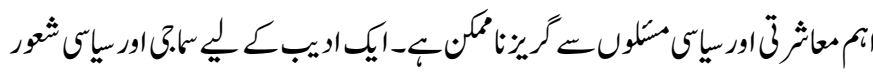

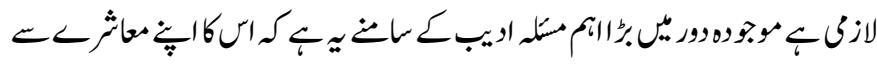




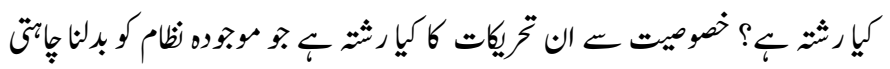

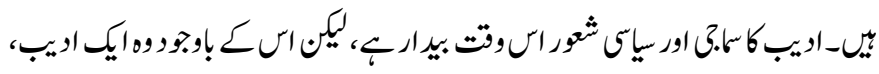

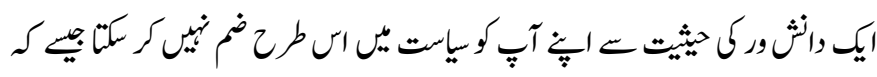

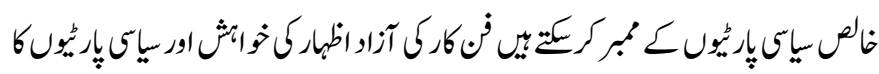

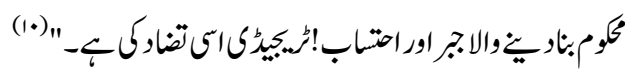

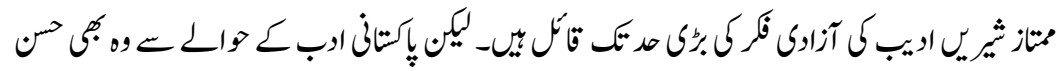

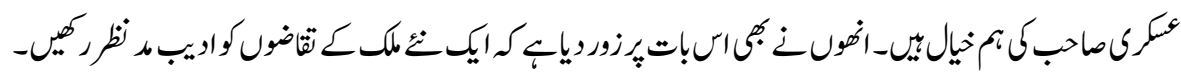

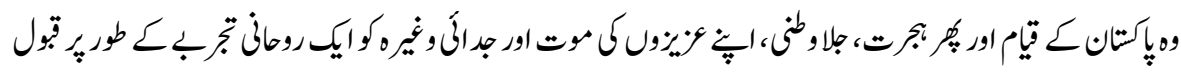

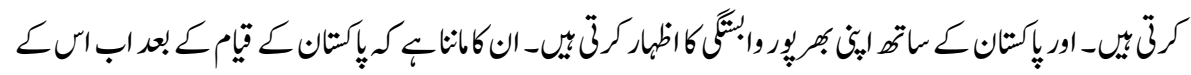

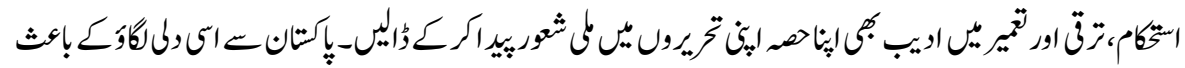

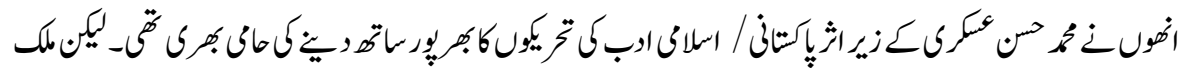

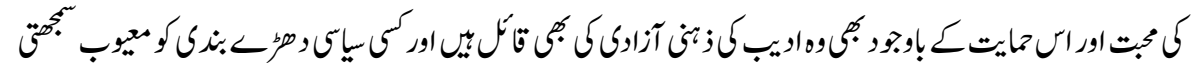

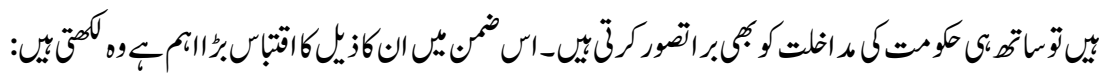

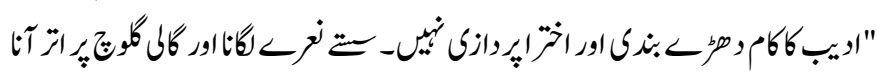

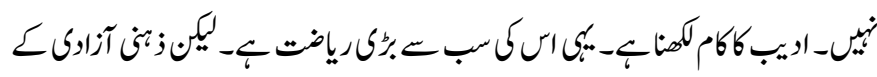

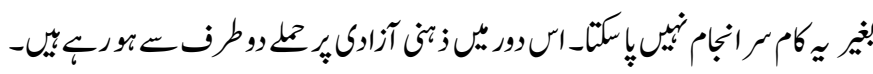

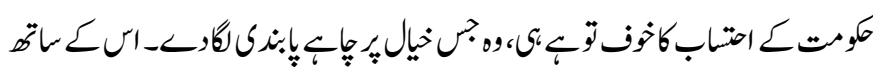

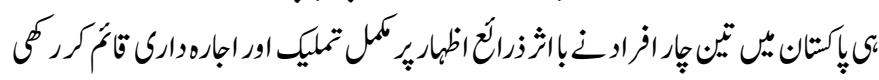

(II)" -4

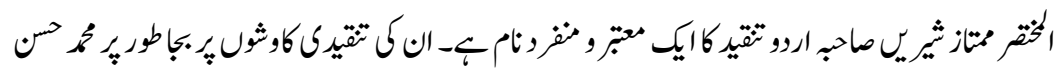

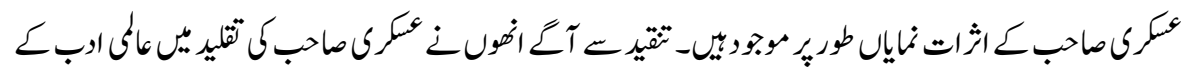

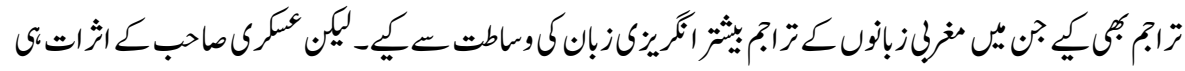

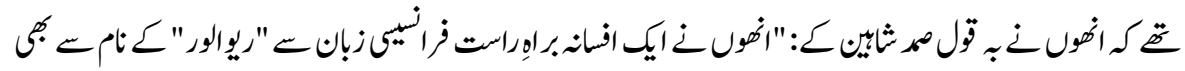

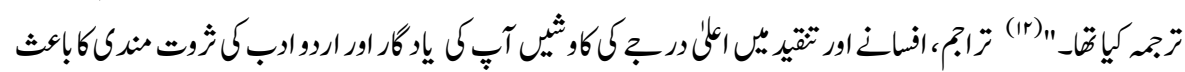




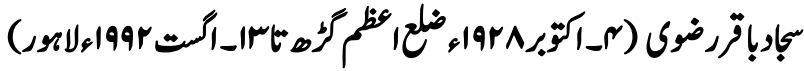

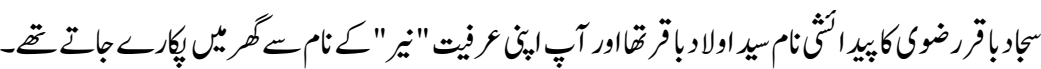

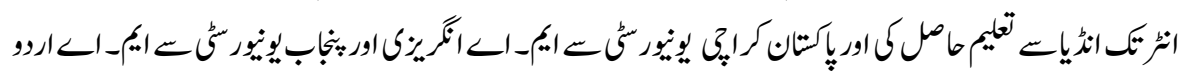

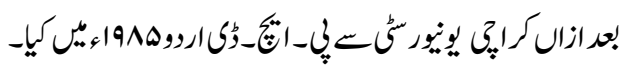

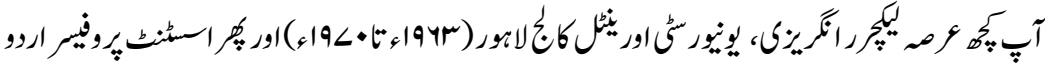

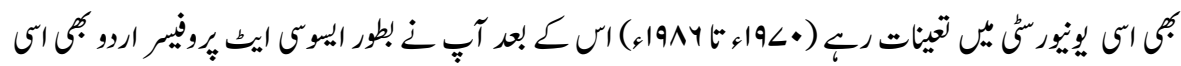

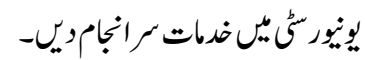

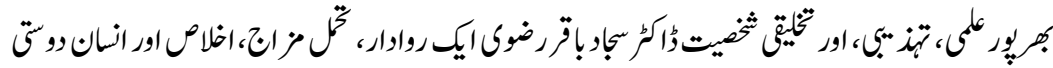

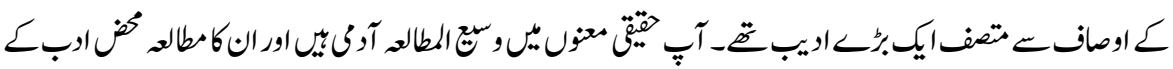

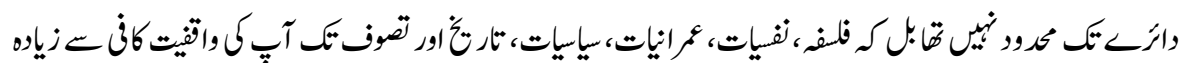

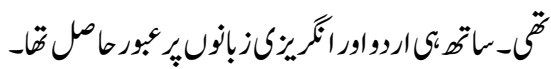

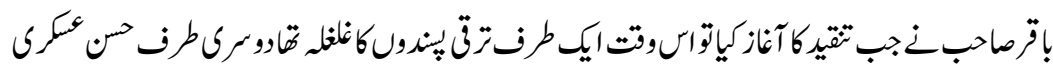

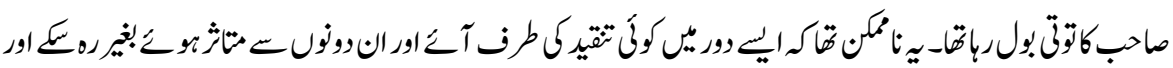

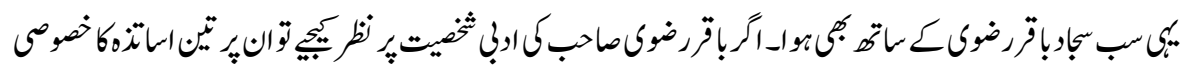

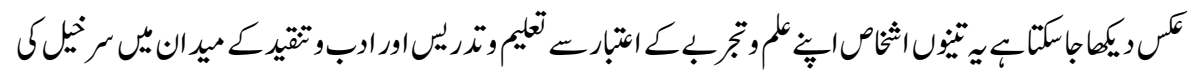

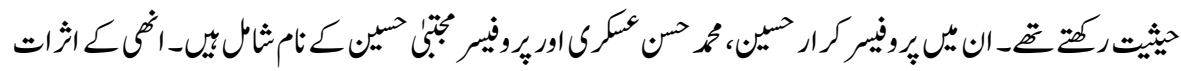

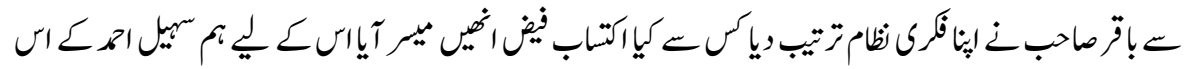
اقتباس كوريمي ليّة:بي:

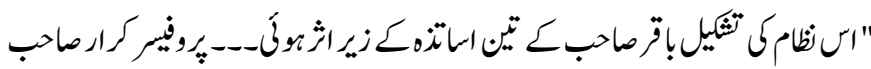

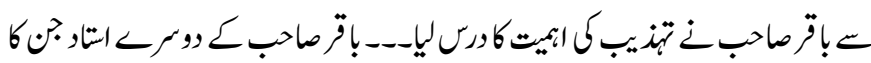

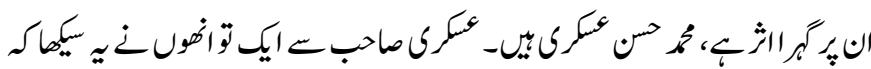

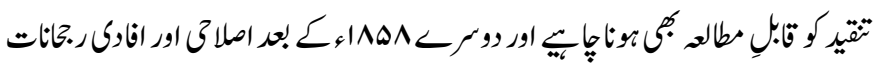

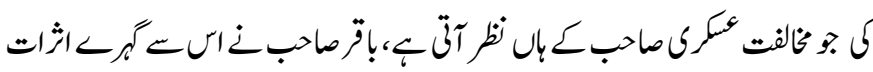

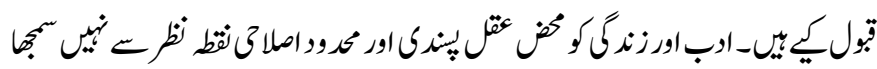

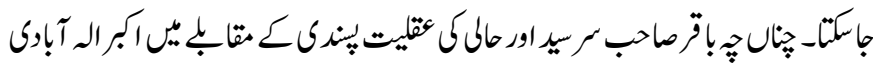




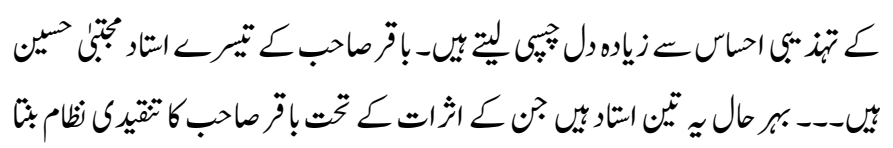

(II) $)-\frac{1}{6}$

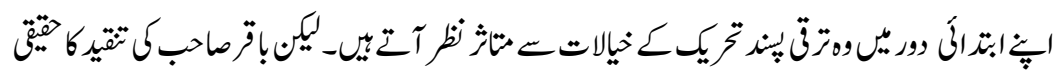

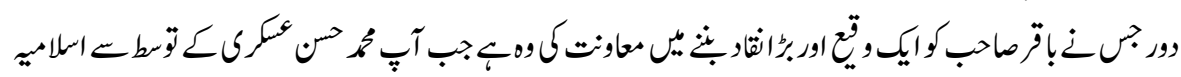

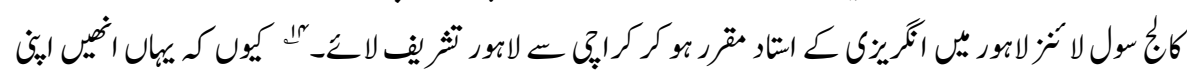

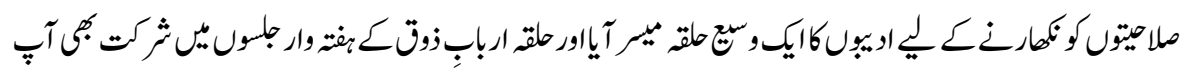

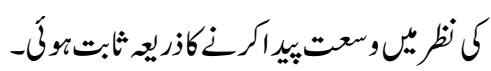

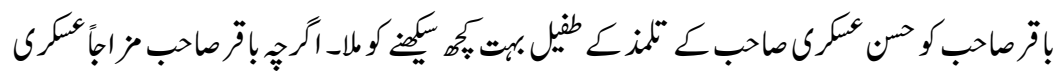

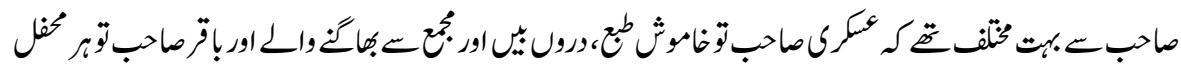

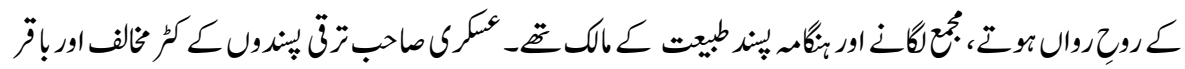

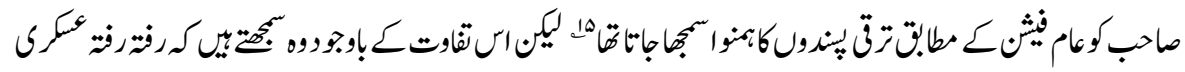

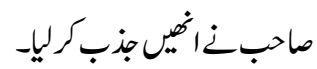

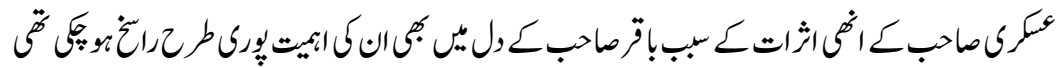

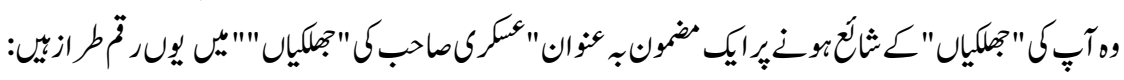

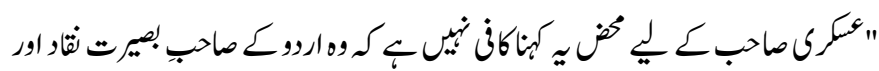

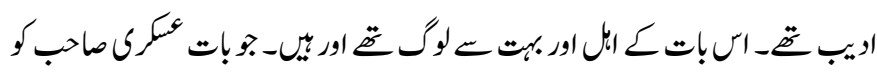

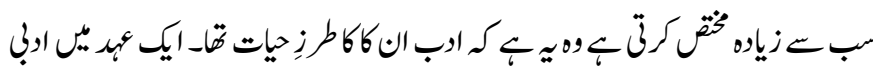

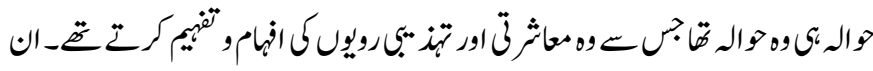

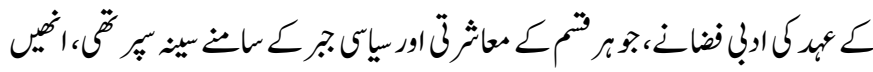

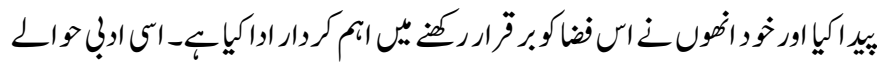

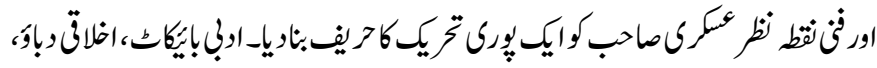

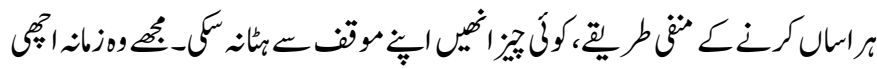

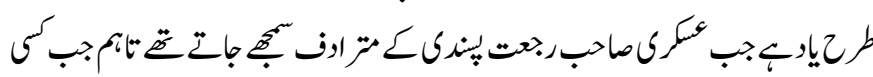




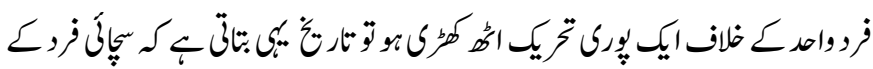

(1)" "(1)

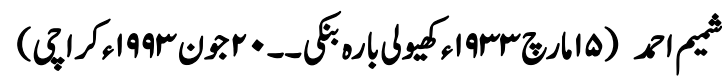

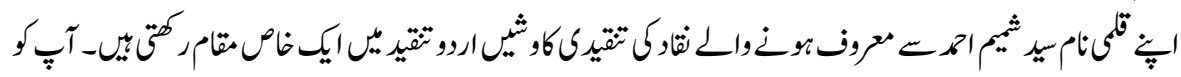

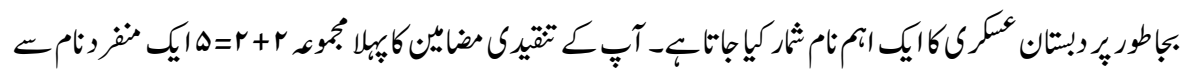

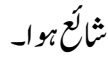

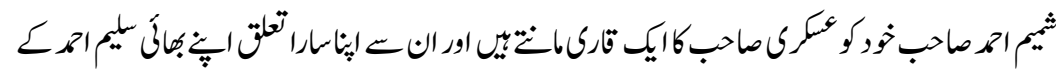

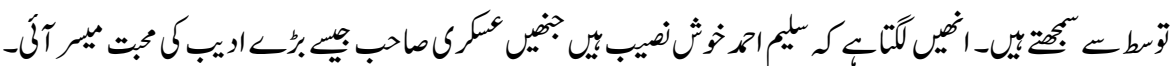

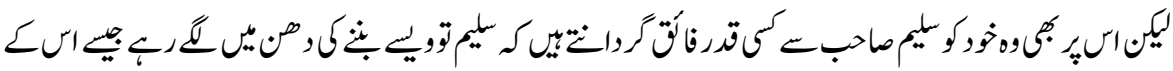

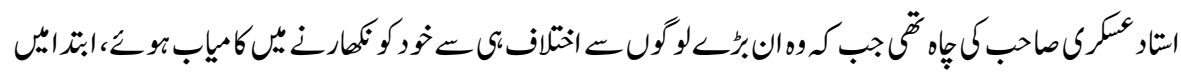

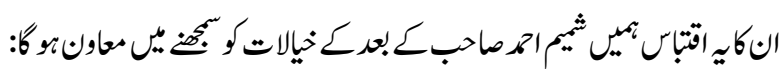

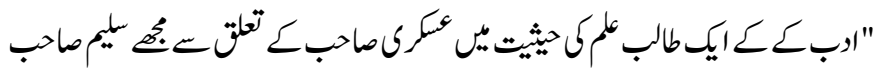

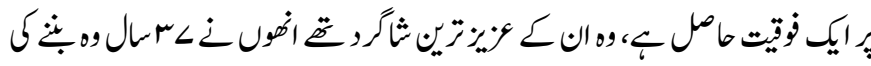

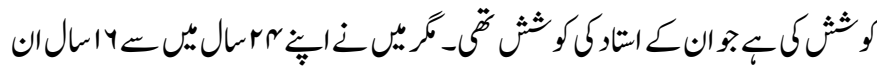

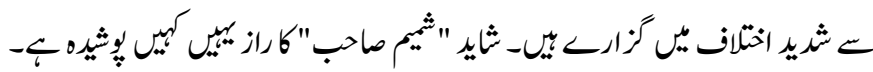

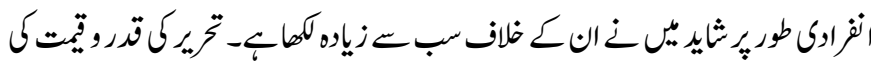

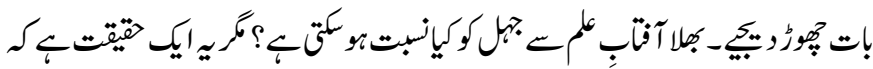

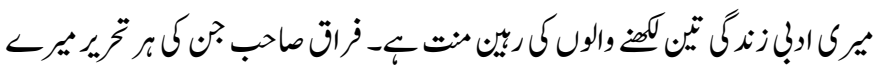

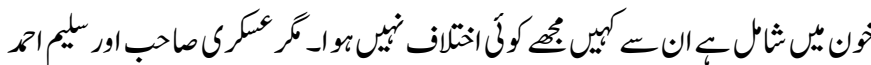

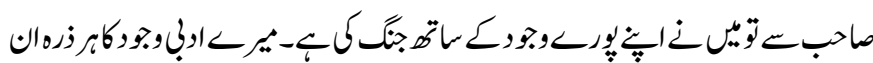

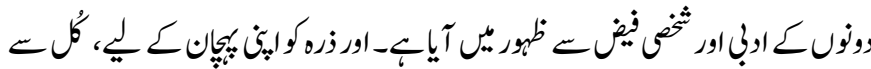

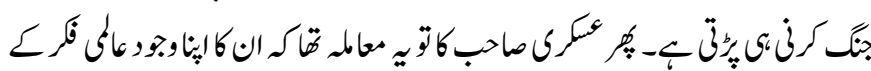

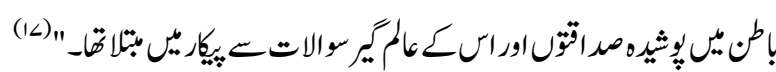

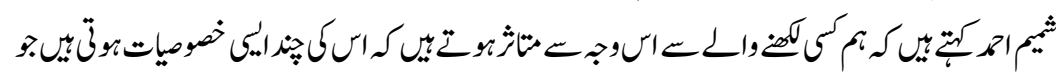

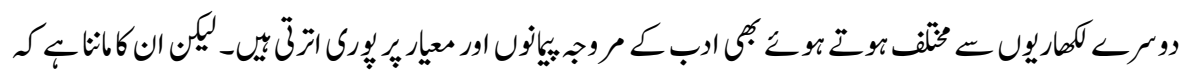




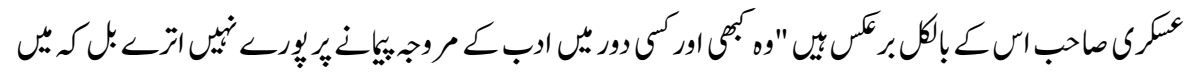

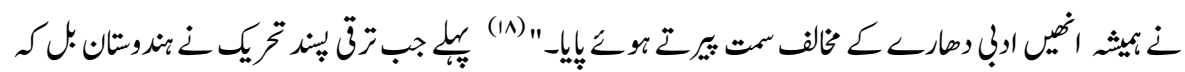

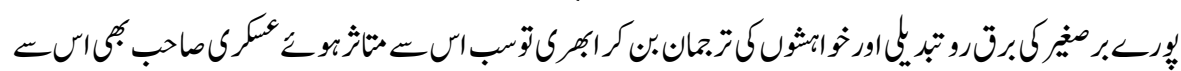

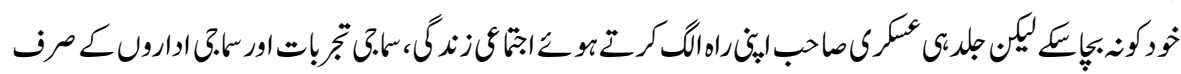

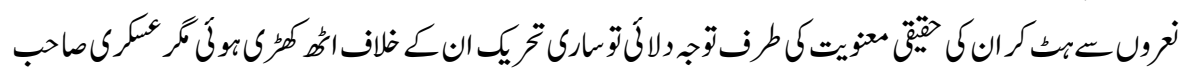

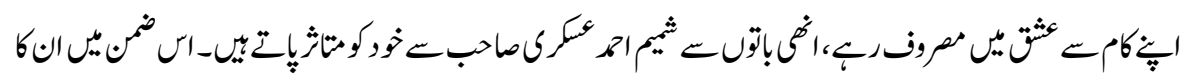

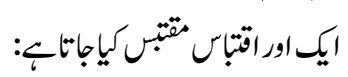

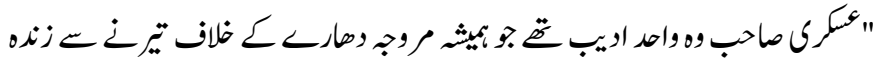

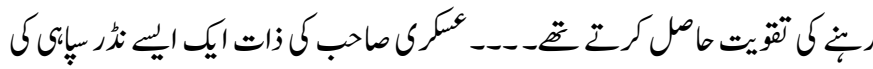

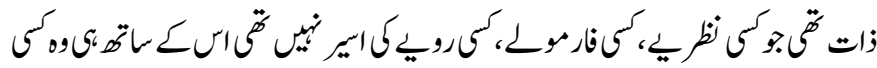

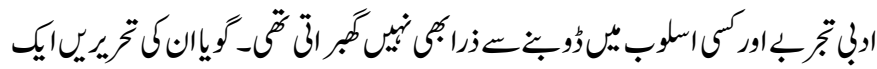

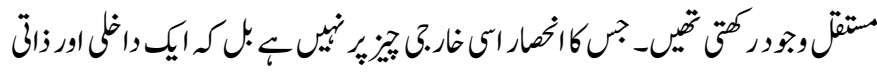

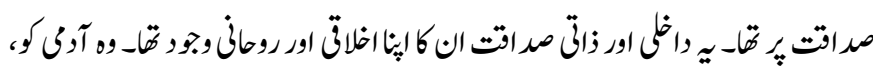

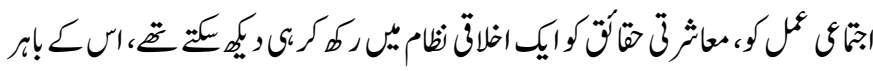

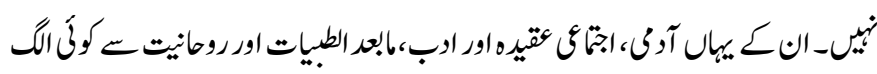

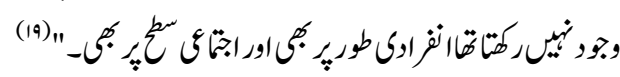

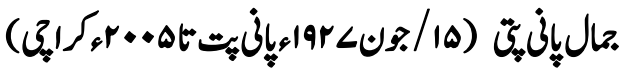

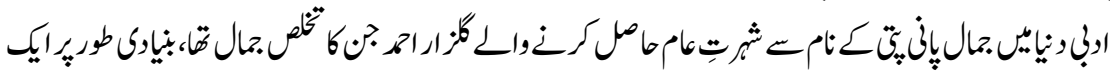

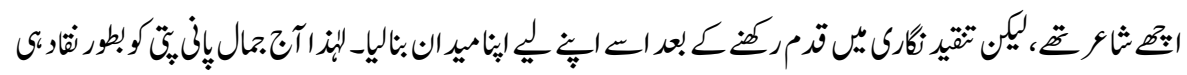

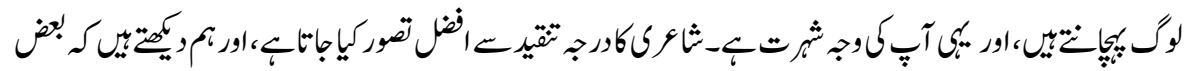

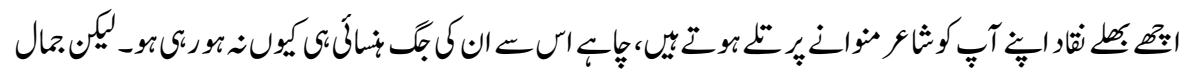

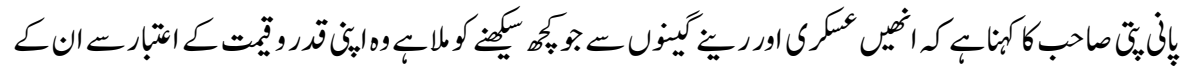

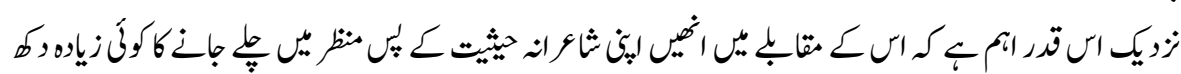




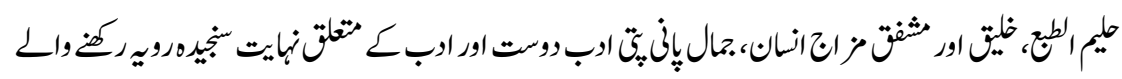

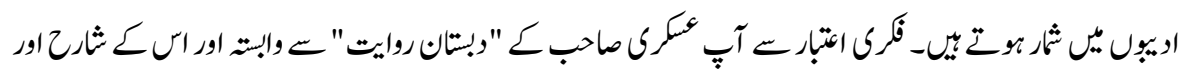

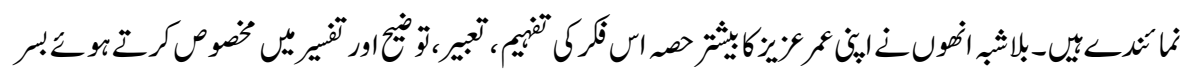

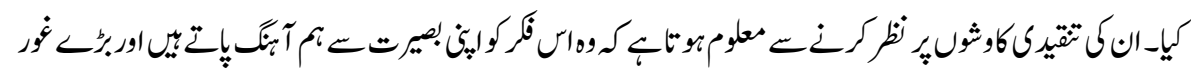

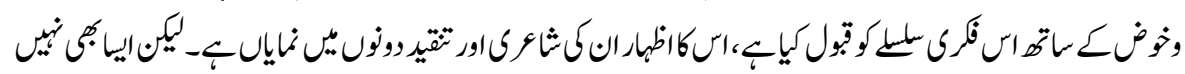

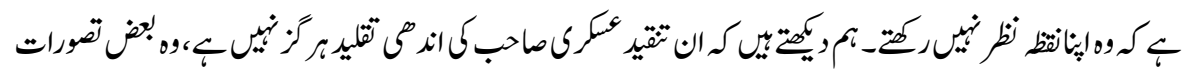

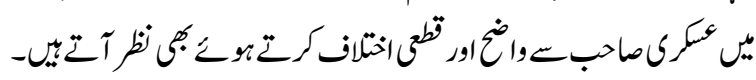

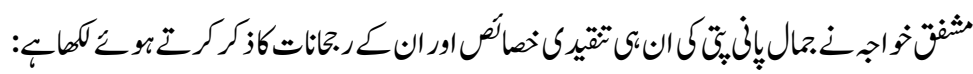

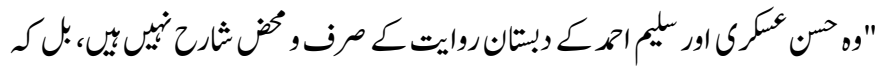

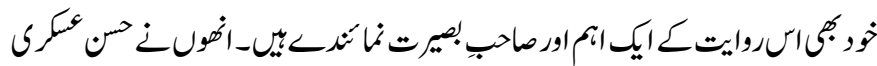

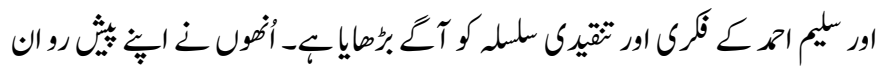

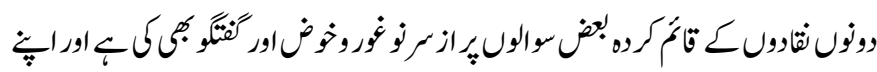

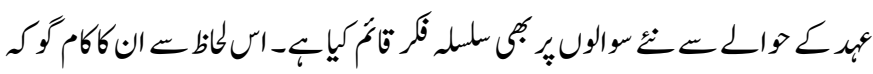

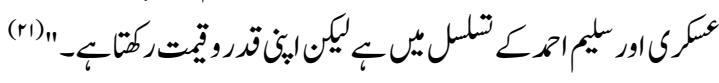

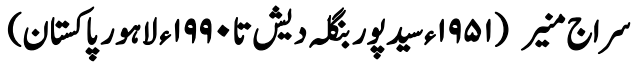

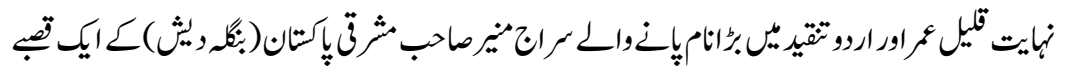

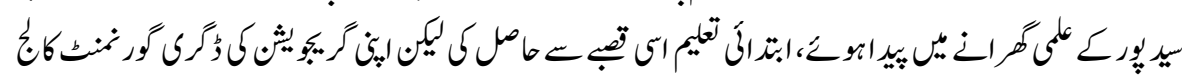

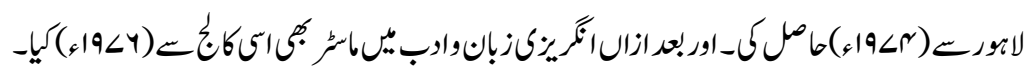

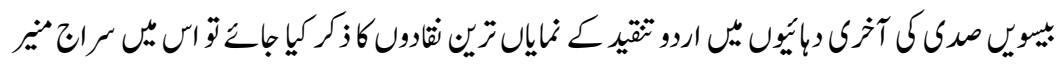

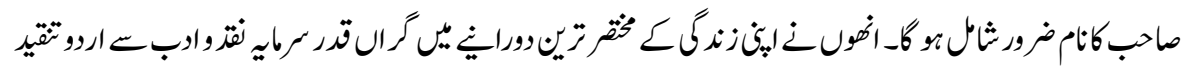

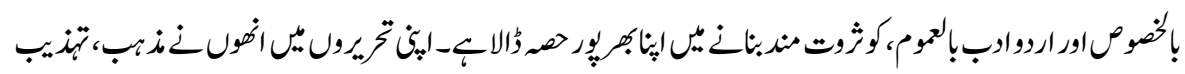

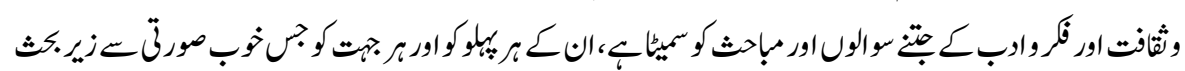

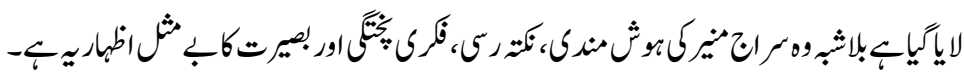

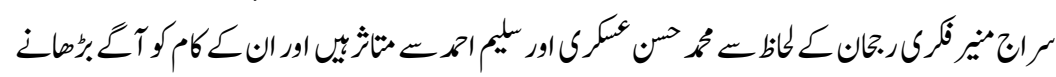

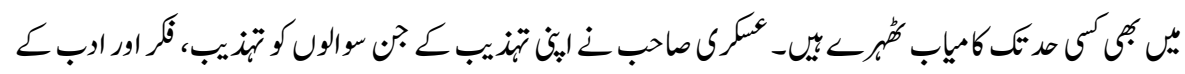




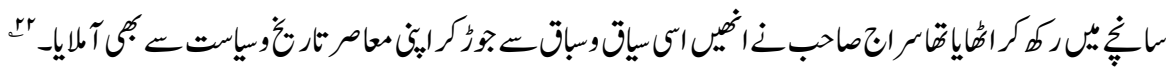

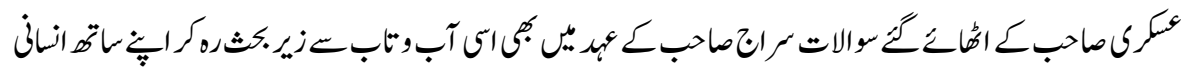

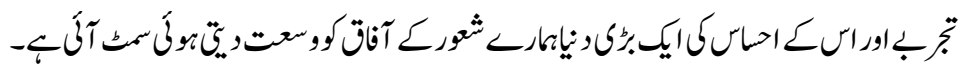

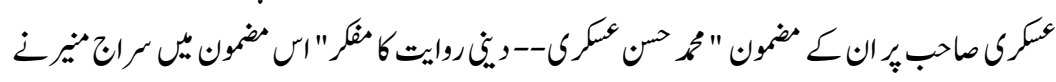

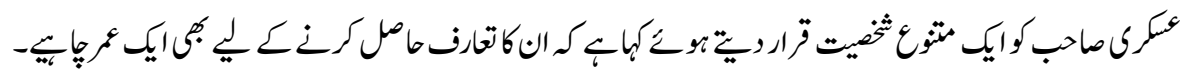

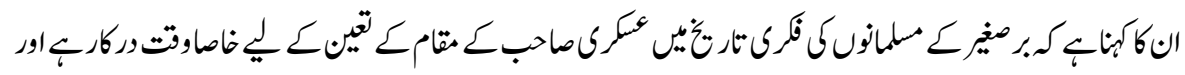

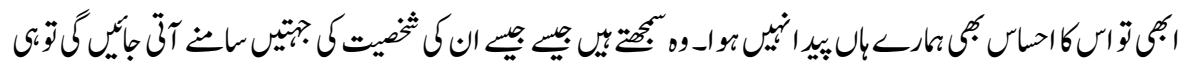

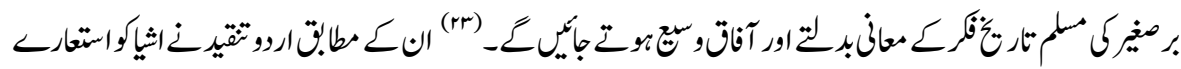

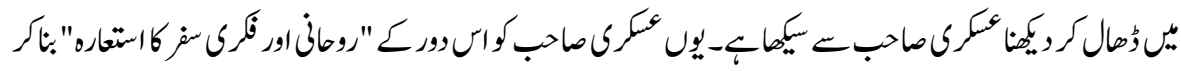

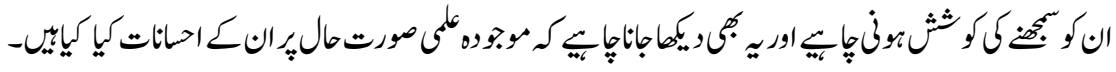

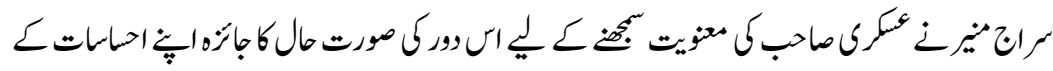

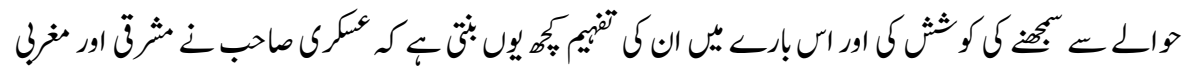

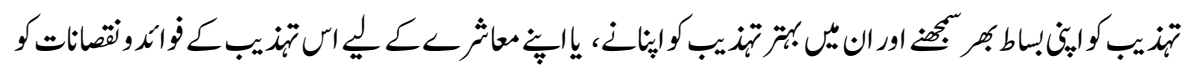

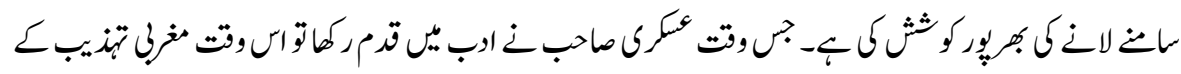

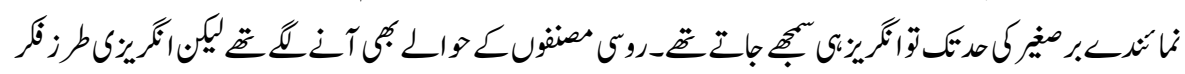

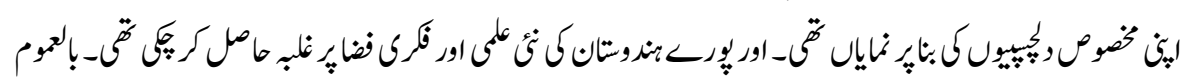

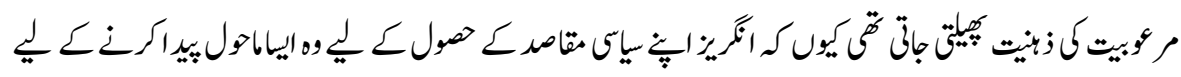

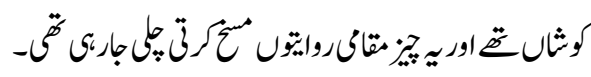

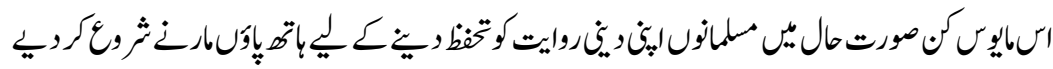

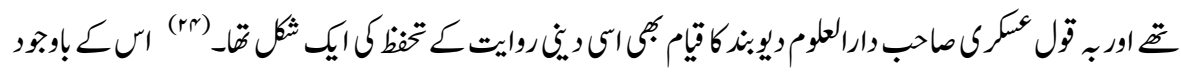

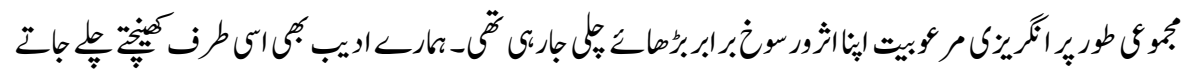

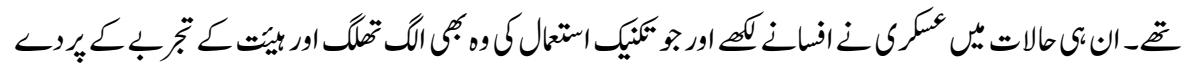

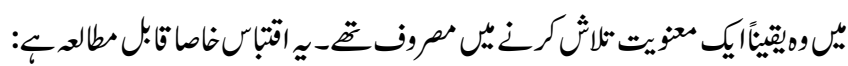

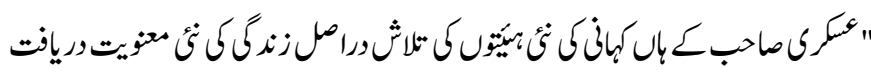

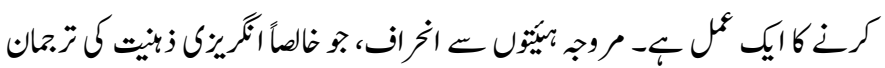




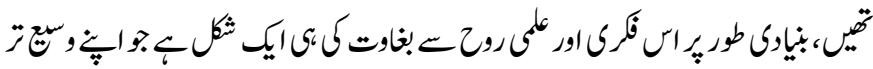

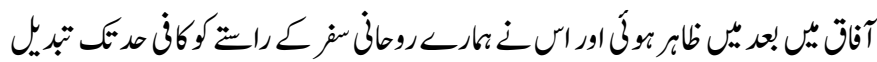

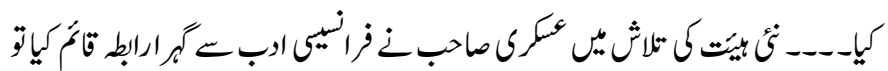

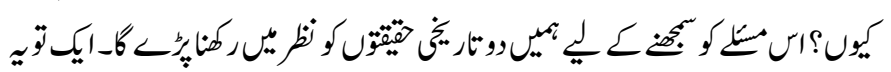

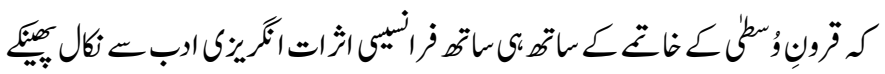

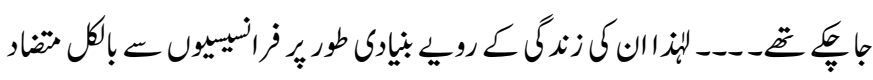

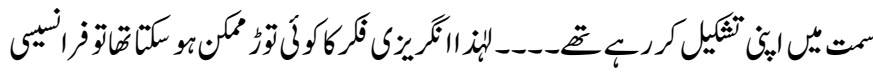

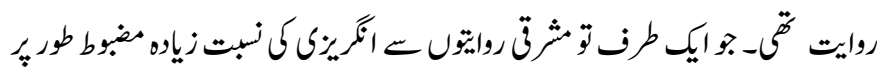

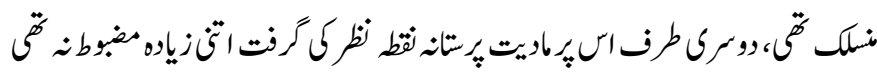

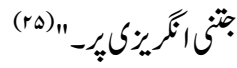

\section{والرجات}

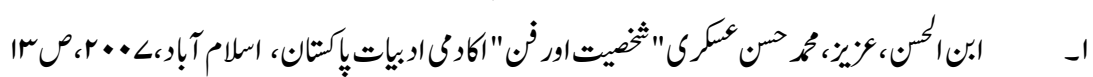

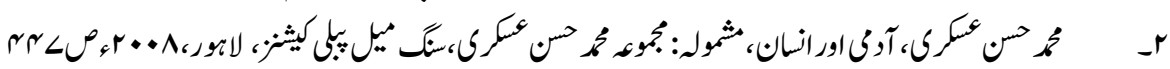

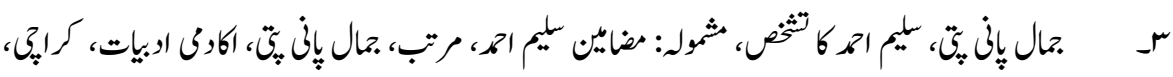

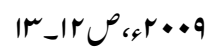

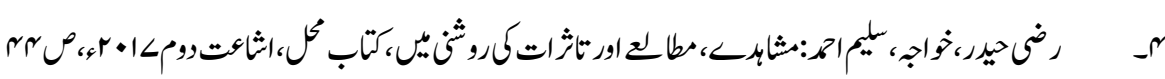

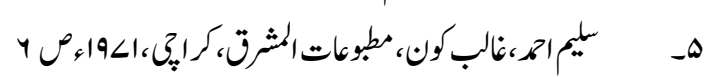

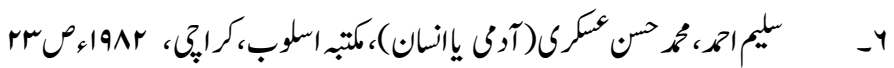

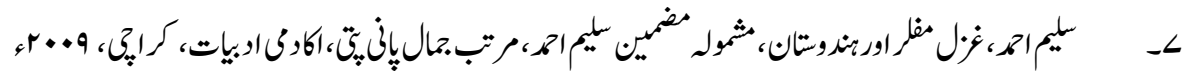

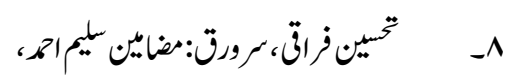

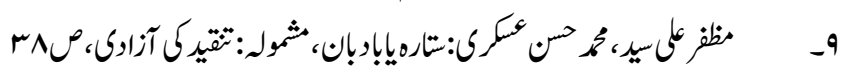

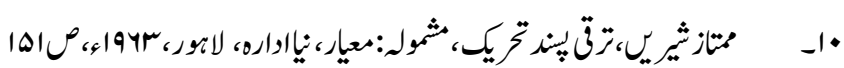

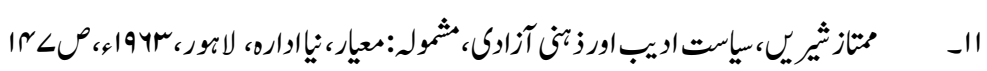




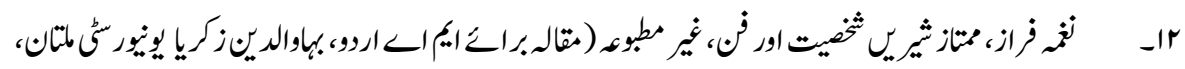

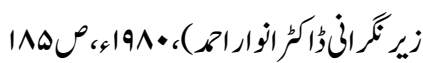

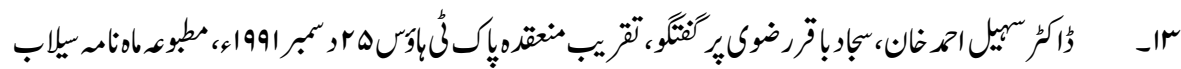

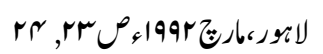

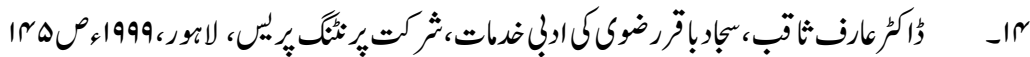

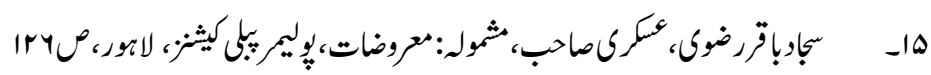

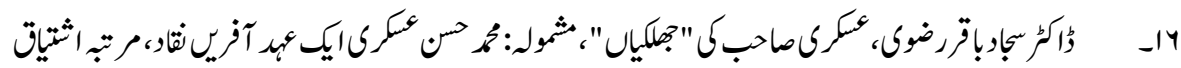

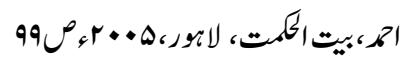

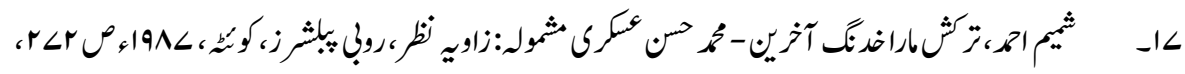

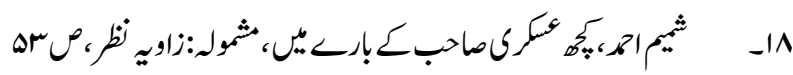

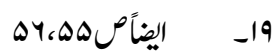

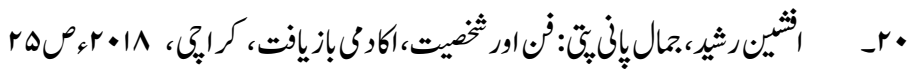

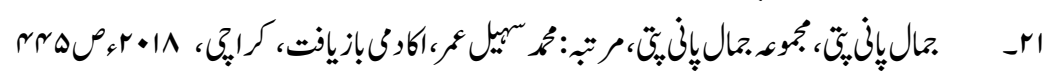
rr

1nerop

$$
\begin{aligned}
& \text { rr } \\
& r<r \text { r } \\
& \text { r r }
\end{aligned}
$$

